\title{
Selection of Soft Magnetic Core Materials Used on an LVDT Prototype
}

\author{
R. Yañez-Valdez ${ }^{1}$, R. Alva-Gallegos ${ }^{2}$, A. Caballero-Ruiz* ${ }^{3}$, L. Ruiz-Huerta ${ }^{4}$ \\ 1,3,4 Laboratorio de Micromecánica y Mecatrónica, CCADET-UNAM. \\ Circuito exterior S/N, C.P. 04510. Cd. Universitaria, México, D.F. \\ *ricardo.yanez@ccadet.unam.mx \\ ${ }^{2}$ Depto. de Mecatrónica. Universidad Tecnológica del Valle de Toluca. \\ Carretera del departamento del DF. Km 7.5, \\ Ejido de Santa María Atarasquillo, Lerma, Estado de México.
}

\begin{abstract}
Traditionally, the use of ferrite as a core of the linear variable differential transformer (LVDT) is suggested in its designs. Nevertheless, problems related to its brittleness and low tensile strength may be considered as important drawbacks for its use as a core material, especially when its geometry is likely to be modified. This work explores other alternatives related to soft magnetic materials, less used in applications of an LVDT core. By means of a decision matrix, from an assortment of different materials, three alternatives were selected. This proposal provides the identification of those materials with higher qualification values to be used as core material. In order to validate the performance of the selected materials, a prototype of LVDT was designed and fabricated. The design was carried out taking into consideration typical performance specifications. Finally, a comparison of the measurements of sensitivity and linearity of the proposed and traditional materials was made.
\end{abstract}

Keywords: linear variable differential transformer, soft magnetic materials, position measurement, prototype.

\section{RESUMEN}

Por tradición, se sugiere el uso de ferrita como núcleo en el diseño de dispositivos LVDT (transformador diferencial variable lineal). Problemas relacionados con la fragilidad de este material hacen poco atractiva su implementación, especialmente cuando su geometría se puede ver modificada. Este trabajo explora otras alternativas en los materiales magnéticamente suaves, menos tradicionales en tal aplicación, con base en requerimientos propuestos. Cada requerimiento está ligado a la implementación y desempeño del LVDT. Esta propuesta provee la identificación de aquellos materiales potencialmente viables para ser usados como núcleos. Para estudiar el comportamiento de los materiales seleccionados, se diseñó y construyó un prototipo de LVDT. El dispositivo LVDT fue diseñado considerando especificaciones de desempeño típicas. Con el prototipo construido, se estudiaron los materiales mejor calificados, identificados con el proceso de selección previo y una matriz de decisión. Finalmente, se realizó una comparación en las mediciones de sensibilidad y linealidad de los materiales seleccionados y el material tradicional.

\section{Introduction}

An LVDT is a common type of electromechanical transducer that can convert the rectilinear motion of an object, which is coupled mechanically, into an electrical signal. It is a position transducer that is noncontact, absolute reading, and has essentially infinite resolution [1]. It is known that this infinite resolution capability is limited only by the noise in the LVDT's signal conditioner and the output display's resolution [2]. The main advantage of the LVDT transducer over other types of displacement transducers is the high degree of robustness, high sensitivity, long operation range, high linearity and contactless sensing. Because there is no physical contact across the sensing element, there is no wear in such element [3]. The linear displacement sensors are deployed in a great number of applications such as position feedback in servomechanisms, pneumatic valves, and many other industrial purposes like manufacturing and process controls and scientific applications [4]. As technology advances, traditional and new displacement sensors are required; they also need to be constantly revised and improved in order to satisfy the requirements of the new promising technologies. Applications of finite element modeling aided analysis have allowed a deeper investigation regarding physical magnitudes, difficult to be measured directly, such as magnetic 
fields, in order to derive the transfer characteristic of an LVDT design [5-6]. More recently developed displacement sensors involve a magnetic interference effect [7-8]. Exploration to replace the core material by an encapsulated ferrofluid has been done [4].

When determining the dimensions of the core to be used with a new LVDT design, the most efficient path to take is to start with the core's dimensions used in an LVDT with similar characteristics to those desired [1]; however, core geometry may have to change. The geometry of some materials, like ferrite, cannot be easily modified, neither manually nor using cutting processes.

Ferrites are essentially ceramics; the raw materials used are oxides or carbonates of the constituent metals. The ingredients are mixed, pre-sintered, milled, formed, shaped, and finally pressed or extruded and fired into their final hard, brittle state [9]. The final material grade determines the necessary purity of the raw materials used. Most common ferrite contains about 50 percent iron oxide. The balance of the remainder of the material determines the type of grade of ferrite. The most common type is made up of oxides of manganese and zinc.
The exploration of alternatives of non-traditional cores is appropriate. To the authors' knowledge, there are no formal proposals reported to select alternatives of soft magnetic materials intended to be applied as LVDT core. The motivation of this work is to provide alternatives of core materials for an LVDT application. In this approach, not only ferrimagnetic but also ferromagnetic materials are included. Therefore, the aim of this work is to provide a simple and effective strategy to select finite options of core materials based on requirements.

\section{Linear variable differential transformer}

Figure 1 shows the components of a typical LVDT. The LVDT sensor is basically a transformer; it comprises one primary coil; two secondary coils, symmetrically spaced with respect to the primary one; and a movable core. The coils are wound onto a tubular coil form. This coil assembly is usually the stationary element of the sensor. The moving element of an LVDT is a separate tubular armature of magnetically permeable core which is free to move axially within the coil's hollow bore, and mechanically coupled to the object whose position is being measured. To obtain a position signal from an LVDT, the primary coil must be driven by an AC power source, and the voltages from the secondary coils must be demodulated.

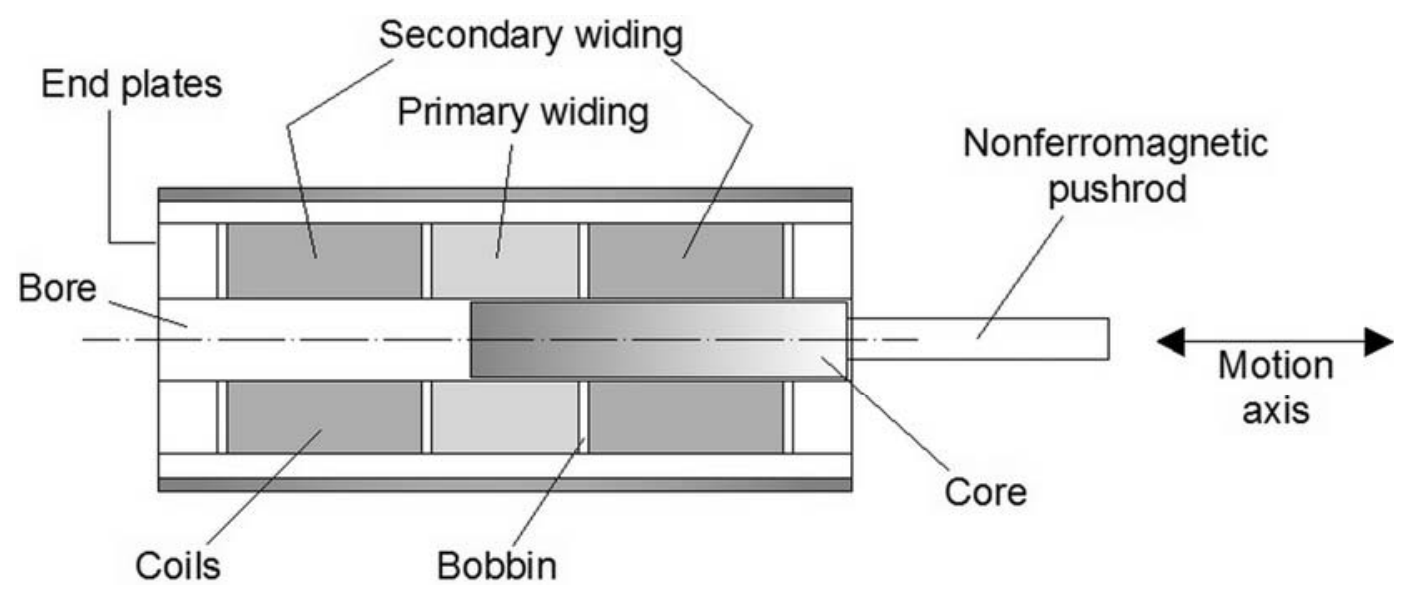

Figure 1. Cutaway view of an LVDT. 
An LVDT core is normally a cylinder made from permeable magnetic material which provides inductive coupling between the primary coil and the secondary coils. The core's material is often some kind of ferromagnetic metal such as iron or ferrimagnetic compounds such as ferrites. The core should be connected mechanically to the component whose displacement must be measured by means of a non-ferromagnetic pushrod. The pushrod can be made from aluminum, plastic or annealed non-magnetic stainless steel.

In the literature it is common to find that ferrites are extensively used as core material [10]. However, a drawback of ferrite cores as opposed to metal cores is their brittleness. Because they are made from a mainly ceramic material, care must be exercised in their handling. Furthermore, ferrites are very hard materials as compared with other metallic materials hence changes on their geometry by means of a machining process become difficult.

\section{Magnetic cores}

Because of their high saturation induction, high permeability, low coercivity, and low core loss, some materials can be grouped under a general heading of magnetically soft materials [11]: ferromagnetic materials, based on iron and nickel; and ferrimagnetic materials, which are based on ceramic oxides of metals. These magnetically soft materials exhibit very high magnetic permeability and are commonly used for these applications [12]. There are several articles [13] highlighting their properties and practical applications. In [11] comparative data for the main classes of soft ferromagnetic and ferrimagnetic materials are given. Generally, those materials with higher saturating flux densities have higher initial permeability and therefore offer higher inductance at the expense of higher core eddy current and hysteresis losses [11]. The highest saturation values are found in the metals and alloys. Powdered iron has a fairly high saturation value, but exhibits low permeabilities.

Magnetic losses are the losses experienced by electrical steel as a result of the same varying magnetic field which is intended to be carried. These losses are of two types: hysteresis and eddy current losses. Hysteresis losses involve the energy loss occurring when the magnetic material goes through a cycling state. Eddy current losses occur when the lines of flux pass through the core, inducing an electrical current in it. Eddy current losses are the greatest cause of loss in magnetic materials [13]. The loss data for electrical steels given by manufacturers are usually of the total core losses and are a combination of hysteresis and eddy current losses. Core loss data is usually available in curve form over the useful range of flux-density [14].

Hysteresis losses are proportional to the flux density and can be depicted as the area inside the hysteresis loop. Eddy current losses quickly increase with frequency [15-16]. In metals these high frequency losses can be reduced by decreasing the thickness of the material perpendicular to the flux flow [17]. Because of its characteristics, practical factors limit the effectiveness of this approach when ferrite material is considered.

The difference in properties and performance of ferrites, as compared with most other magnetic soft materials, is due to the fact that ferrites are oxide materials rather than metals. The highest magnetic moments and therefore the highest saturation magnetizations are to be found in the metals themselves or in alloys of these metals. Oxides, on the other hand, suffer from a dilution effect of the large oxygen ions in the crystal lattice. The oxygen ions insulate the metal ions and therefore greatly increase the resistivity. This property makes ferrite especially useful at higher frequencies [18]. Ferrite cores have drawbacks however: because they are made from a homogeneous material composed of various oxides with iron oxide as its main constituent, ferrite cores present low tensile strength thus changes on their geometry by means of a machining process become difficult. Moreover, they require careful handling because of their brittleness [19].

\section{Core material's requirements and selection}

In this section, the requirements to select core materials are proposed. The core material must be selected keeping in mind that it has to provide the desired amount of inductance change as it moves 


\begin{tabular}{c|c|l} 
Requirement & Weighting & \multicolumn{1}{c}{ Commentary } \\
\hline \hline High availability & $35 \%$ & Linked to the commercial acquisition of the core material. \\
\hline High ductility & $30 \%$ & $\begin{array}{l}\text { Linked to the implementation of the core in required } \\
\text { dimensions. }\end{array}$ \\
\hline $\begin{array}{c}\text { High } \\
\text { permeability }\end{array}$ & $20 \%$ & $\begin{array}{l}\text { Directly linked to the performance and reliability of the } \\
\text { device. }\end{array}$ \\
\hline Low CTE & $10 \%$ & $\begin{array}{l}\text { The variations in the reading can be compensated knowing } \\
\text { the temperature of the core. }\end{array}$ \\
\hline Low density & $5 \%$ & Its relevancy depends on the application of the device. \\
\hline
\end{tabular}

Table 1. Weighting of the requirements.

into the coil. It is desirable for the core to have some additional favorable physical properties which include high initial and constant permeability, low density, temperature stability, and high ductility. Additionally, a more specific requirement regarding its feasibility is the availability of each material, preferably in such form that facilitates its adaptability to the device. Following, a brief description of each property is provided:

- High availability on the market: It is the most important parameter since this condition ensures the material is found easily; therefore, it heads the list of priorities.

- High ductility: The mass also can diminish, modifying the geometry of the core by means of conventional manufacturing; hence, the material has to be capable of being deformed or machined without breaking.

- High permeability: It is important for soft magnetic materials since it indicates how much magnetic induction is generated in a magnetic field.

- Low coefficient of thermal expansion (CTE): When the degree of expansion caused by the change in temperature is low, the variations in the output signal are also low. With thermal expansions and contractions of the core, the magnetic induction increases or decreases, this fact affects the precision of the device.

- Low density: Different materials usually have different densities hence density is an important concept regarding the heaviness of objects with constant volume. When the density of the core, and therefore, its mass, is low, the force required to displace it is also low. This consideration depends on the application of the device and must not alter the performance of the system to be evaluated.

In order to select some materials to be used as LVDT core, a decision matrix was performed. Table 1 shows the weight of each requirement in terms of percentage, for a total of 100 percent. It had to be done with caution to assure that they are properly weighted in accordance with the importance of each criterion.

After reviewing 100 soft magnetic materials and collecting each of the described requirements [11$13,16,18,20-23]$, three groups can be distinguished, mainly arranged by their value of relative permeability.

- The first group holds those values of highest relative permeability $\mu_{\mathrm{r}}$ : such values are between $1 \mathrm{e}^{5}<\mu_{\max }<1 \mathrm{e}^{6}$. In this group, some materials appear such as Supermalloy $(79 \% \mathrm{Ni}, 16 \% \mathrm{Fe}$, $5 \% \mathrm{Mo})$, Sendust $(6.2 \% \mathrm{Al}, 9.6 \% \mathrm{Si}$, rest $\mathrm{Fe})$, $\mathrm{FeNi}$ and FeCo alloys.

- The second group holds those values of medium relative permeability, such values are between $5 \mathrm{e}^{4}<\mu_{\max }<1 \mathrm{e}^{5}$. In this group some materials appear such as Permalloy $(78.5 \% \mathrm{Ni}, 3.8 \% \mathrm{Mo}$, $17.7 \% \mathrm{Fe})$, Supermendur ( $49 \% \mathrm{Fe}, 49 \% \mathrm{Co}, 2 \% \mathrm{~V})$, and Alnico $\mathrm{V}(24 \% \mathrm{Co}, 14 \% \mathrm{Ni}, 8 \% \mathrm{Al}, 3 \% \mathrm{Cu}$, $51 \% \mathrm{Fe})$.

- The third group holds those values of lower relative permeability; such values are between $5 \mathrm{e}^{3}<\mu_{\max }<1 \mathrm{e}^{4}$. In this group, some materials appear such as Si-Fe (un-oriented $96 \% \mathrm{Fe}$, 


\begin{tabular}{|c|c|c|c|c|c|c|}
\hline Group & $\begin{array}{c}\text { Soft magnetic } \\
\text { material }\end{array}$ & Composition & $\begin{array}{c}\text { Permeability } \\
{\left[\mu_{\mathrm{r}}\right]}\end{array}$ & $\begin{array}{c}\text { Ductility } \\
{[\%]}\end{array}$ & $\begin{array}{c}\text { CTE } \\
{\left[10^{-6} /{ }^{\circ} \mathrm{C}\right]}\end{array}$ & $\begin{array}{l}\text { Density } \\
{\left[\mathrm{g} / \mathrm{cm}^{3}\right]}\end{array}$ \\
\hline \multirow{4}{*}{1} & Supermalloy & $79 \% \mathrm{Ni}-4 \% \mathrm{Mo}$ & 1000000 & 38 & 13 & 8.72 \\
\hline & Supermalloy & $79 \% \mathrm{Ni}, 16 \% \mathrm{Fe}, 5 \% \mathrm{Mo}$ & 1000000 & 32 & 13 & 8.72 \\
\hline & Nickel Steel & $\mathrm{Fe}, 78 \% \mathrm{Ni}$ & 300000 & 30 & 17 & 8.61 \\
\hline & Iron & $99,95 \%$ pure & 200000 & 24 & 11 & 7.86 \\
\hline \multirow{5}{*}{2} & Permalloy Mo & $78,5 \% \mathrm{Ni}, 3,8 \% \mathrm{Mo}, 17,7 \% \mathrm{Fe}$ & 75000 & 36 & 13 & 8.72 \\
\hline & Permalloy $\mathrm{Cr}$ & $78,5 \% \mathrm{Ni}, 3,8 \% \mathrm{Cr}, 17,7 \% \mathrm{Fe}$ & 62000 & 36 & 13 & 8.72 \\
\hline & Nickel steel & $\mathrm{Fe}, 50 \% \mathrm{Ni}$ & 60000 & 30 & 9 & 8.17 \\
\hline & Supermendur & $49 \% \mathrm{Fe}, 49 \% \mathrm{Co}, 2 \% \mathrm{~V}$ & 60000 & 37 & 9.5 & 8.20 \\
\hline & Alnico V & $\begin{array}{c}24 \% \mathrm{Co}, 14 \% \mathrm{Ni}, 8 \% \mathrm{Al}, \\
3 \% \mathrm{Cu}, 51 \% \mathrm{Fe}\end{array}$ & 53000 & Fragile & 11.4 & 7.30 \\
\hline \multirow{2}{*}{3} & Permendur & $50 \% \mathrm{Fe}, 50 \% \mathrm{Co}$ & 8000 & 6 & 9.5 & 8.30 \\
\hline & $\mathrm{Si}-\mathrm{Fe}$ & un-oriented $96 \% \mathrm{Fe}, 4 \% \mathrm{Si}$ & 7000 & 24 & 11.6 & 7.48 \\
\hline
\end{tabular}

Table 2. Specifications of soft magnetic materials.

\begin{tabular}{|c|c|c|c|}
\hline Group & $\begin{array}{l}\text { Soft magnetic material } \\
\text { (Composition) }\end{array}$ & $\begin{array}{c}\text { Saturation magnetization at } \mathrm{H}=0.02 \mathrm{~A} / \mathrm{m} \\
{[\mathrm{T}]}\end{array}$ & $\begin{array}{l}\text { Core losses [W/Kg] } \\
\left(\mathrm{f} / \mathrm{B}_{\max } \mathrm{Hz} / \mathrm{T}\right)\end{array}$ \\
\hline \multirow{4}{*}{1} & $\begin{array}{l}\text { Supermalloy } \\
(79 \% \mathrm{Ni}-4 \% \mathrm{Mo})\end{array}$ & 0.80 & $\begin{array}{c}40 \\
(50 \mathrm{k} / 0.2)\end{array}$ \\
\hline & $\begin{array}{c}\text { Supermalloy } \\
(79 \% \mathrm{Ni}, 16 \% \mathrm{Fe}, 5 \% \mathrm{Mo})\end{array}$ & 0.80 & $\begin{array}{c}3.75 \\
(3 \mathrm{k} / 0.5)\end{array}$ \\
\hline & $\begin{array}{l}\text { Nickel Steel } \\
(\mathrm{Fe}, 78 \% \mathrm{Ni})\end{array}$ & 0.80 & $\begin{array}{c}0.06 \\
(50 / 1.0)\end{array}$ \\
\hline & $\begin{array}{c}\text { Iron } \\
(99,95 \% \text { pure })\end{array}$ & 2.15 & $\begin{array}{c}5 \\
(50 / 1.0)\end{array}$ \\
\hline \multirow{5}{*}{2} & $\begin{array}{c}\text { Permalloy Mo } \\
(78,5 \% \mathrm{Ni}, 3,8 \% \mathrm{Mo}, 17,7 \% \mathrm{Fe})\end{array}$ & 0.85 & $\begin{array}{c}5.55 \\
(3 \mathrm{k} / 0.5)\end{array}$ \\
\hline & $\begin{array}{c}\text { Permalloy } \mathrm{Cr} \\
(78,5 \% \mathrm{Ni}, 3,8 \% \mathrm{Cr}, 17,7 \% \mathrm{Fe})\end{array}$ & 0.80 & $\begin{array}{c}0.75 \\
(60 / 1.0)\end{array}$ \\
\hline & $\begin{array}{l}\text { Nickel steel } \\
\text { (Fe, } 50 \% \mathrm{Ni})\end{array}$ & 1.2 & $\begin{array}{c}0.2 \\
(50 / 1.0)\end{array}$ \\
\hline & $\begin{array}{c}\text { Supermendur } \\
(49 \% \mathrm{Fe}, 49 \% \mathrm{Co}, 2 \% \mathrm{~V})\end{array}$ & 2.3 & $\begin{array}{c}30 \\
(10 \mathrm{k} / 0.2)\end{array}$ \\
\hline & $\begin{array}{c}\text { Alnico V } \\
(24 \% \mathrm{Co}, 14 \% \mathrm{Ni}, 8 \% \mathrm{Al}, 3 \% \mathrm{Cu}, 51 \% \mathrm{Fe})\end{array}$ & 1.27 & --- \\
\hline \multirow{2}{*}{3} & $\begin{array}{c}\text { Permendur } \\
(50 \% \mathrm{Fe}, 50 \% \mathrm{Co})\end{array}$ & 2.45 & $\begin{array}{c}2.2 \\
(60 / 2.0)\end{array}$ \\
\hline & $\begin{array}{c}\text { Si-Fe } \\
\text { (un-oriented } 96 \% \mathrm{Fe}, 4 \% \mathrm{Si} \text { ) }\end{array}$ & 2.14 & $\begin{array}{c}2.7 \\
(60 / 1.0)\end{array}$ \\
\hline
\end{tabular}

$\mathrm{H}=$ magnetizing force, $\mathrm{B}=$ flux density.

Table 3. Magnetic characteristics of soft magnetic materials. 


\begin{tabular}{|c|c|c|c|c|c|c|c|c|c|c|c|c|c|}
\hline \multirow{2}{*}{$\begin{array}{c}\text { Grou } \\
\mathrm{p}\end{array}$} & \multirow{2}{*}{$\begin{array}{l}\text { Soft magnetic } \\
\text { material }\end{array}$} & \multicolumn{2}{|c|}{ Availability } & \multicolumn{2}{|c|}{$\begin{array}{c}\text { Permeability } \\
{\left[\mu_{\mathrm{r}}\right]}\end{array}$} & \multicolumn{2}{|c|}{$\begin{array}{c}\text { CTE } \\
{\left[10^{-6} /{ }^{\circ} \mathrm{C}\right]}\end{array}$} & \multicolumn{2}{|c|}{$\begin{array}{c}\text { Ductility } \\
{[\%]}\end{array}$} & \multicolumn{2}{|c|}{$\begin{array}{l}\text { Density } \\
{\left[\mathrm{g} / \mathrm{cm}^{3}\right]}\end{array}$} & \multicolumn{2}{|c|}{ Totals } \\
\hline & & $Q$ & $\mathrm{~W}$ & $\mathrm{Q}$ & $\mathrm{W}$ & $Q$ & W & $Q$ & W & Q & $\mathrm{W}$ & $\sum W$ & $\mathrm{R}$ \\
\hline \multirow{4}{*}{1} & $\begin{array}{c}\text { Supermalloy } \mathrm{Ni}- \\
\text { Mo }\end{array}$ & 1 & 0.35 & 11 & 2.2 & 5 & 0.5 & 11 & 3.3 & 4 & 0.2 & 6.55 & 5 \\
\hline & $\begin{array}{c}\text { Supermalloy Ni- } \\
\text { Fe-Mo }\end{array}$ & 1 & 0.35 & 10 & 2 & 5 & 0.5 & 7 & 2.1 & 4 & 0.2 & 5.15 & 8 \\
\hline & $\begin{array}{c}\text { Nickel steel Fe, } \\
78 \% \mathrm{Ni} \\
\end{array}$ & 11 & 3.85 & 9 & 1.8 & 1 & 0.1 & 6 & 1.8 & 5 & 0.25 & 7.8 & 4 \\
\hline & Iron & 11 & 3.85 & 8 & 1.6 & 8 & 0.8 & 4 & 1.2 & 9 & 0.45 & 7.9 & 3 \\
\hline \multirow{5}{*}{2} & Permalloy Mo & 1 & 0.35 & 7 & 1.4 & 5 & 0.5 & 9 & 2.7 & 4 & 0.2 & 5.15 & 9 \\
\hline & Permalloy $\mathrm{Cr}$ & 1 & 0.35 & 6 & 1.2 & 5 & 0.5 & 9 & 2.7 & 4 & 0.2 & 4.95 & 10 \\
\hline & $\begin{array}{c}\text { Nickel steel Fe, } \\
50 \% \mathrm{Ni} \\
\end{array}$ & 11 & 3.85 & 5 & 1 & 11 & 1.1 & 6 & 1.8 & 8 & 0.4 & 8.15 & 2 \\
\hline & $\begin{array}{c}\text { Supermendur } \\
\text { Fe-Co-V }\end{array}$ & 11 & 3.85 & 4 & 0.8 & 10 & 1 & 10 & 3 & 7 & 0.35 & 9 & 1 \\
\hline & Alnico V & 11 & 3.85 & 3 & 0.6 & 7 & 0.7 & 1 & 0.3 & 11 & 0.55 & 6 & 7 \\
\hline \multirow{2}{*}{3} & $\begin{array}{c}\text { Permendur } \\
\text { Fe-Co }\end{array}$ & 11 & 3.85 & 2 & 0.4 & 10 & 1 & 2 & 0.6 & 6 & 0.3 & 6.15 & 6 \\
\hline & Si-Fe & 1 & 0.35 & 1 & 0.2 & 6 & 0.6 & 4 & 1.2 & 10 & 0.5 & 2.85 & 11 \\
\hline
\end{tabular}

$\mathrm{Q}=$ Qualification (from 11-Excellent to 1-Poor), $\mathrm{W}=$ weight (\%), $\mathrm{R}=$ rating.

Table 4. Summary of soft magnetic materials.

- 4\% $\mathrm{Si}$ ), Permendur (50\%Fe, 50\% $\mathrm{Co}$ ), and Ferrite $\left(36 \% \mathrm{NiO}-\mathrm{Fe}_{2} \mathrm{O}_{3}, 64 \% \mathrm{ZnO}-\mathrm{Fe}_{2} \mathrm{O}_{3}\right)$.

In Table 2, special attention was paid to those groups with higher values of permeability and to the most likely to be commercially purchased. In addition, Table 3 shows some magnetic characteristics of those groups for comparison purposes [13, 24-26] while Table 4 shows those selected materials that meet each requirement.

A rating for the selected materials is given in Table 4. The rating of each material is a function of the compliance with each requirement. With regard to the availability of each soft magnetic material, those materials that cannot be purchased commercially in a round rod were rated with a low score. On the other hand, those materials that can be purchased commercially in a round rod were rated with a high score. In order to know the availability of each material, an exhaustive search in the international market has been done. The best positioned material is Supermendur $(49 \% \mathrm{Fe}$, $49 \% \mathrm{Co}, 2 \% \mathrm{~V}$ ), followed by nickel steel and iron. It should be clarified that the cost of each material has not been determined yet. This aim has been achieved after developing a selection process in which the main properties related to the implementation and performance of a core for the application of an LVDT have been included. Next, a prototype of LDTV is presented and an experimental procedure is discussed.

\section{Prototype of LVDT}

\section{Design}

LVDTs require a set of driving and conditioning electronic circuits. A typical LVDT is designed as a sensing element with a core, the electronic circuit being considered as a separate device. Several styles and housing diameters of LVDTs are standard in the industry. The basic style includes an LVDT housing and a separate core. In this report, an oscilloscope and a wave generator were used instead of the electronic circuit; therefore, the design of the testing bench includes only the mechanical design and the calculations of the coils. The core has internal threads used to attach a non-ferromagnetic pushrod. A prototype of LDTV was designed and developed following typical performance specifications for a basic style sensor $[1,3,27-28]$ : 


\begin{tabular}{|c|c|}
\hline $\begin{array}{l}\text { Excitation voltage } \\
\text { range }\end{array}$ & $3 \mathrm{~V}<\mathrm{V}_{\mathrm{e}}<15 \mathrm{~V}$ \\
\hline $\begin{array}{l}\text { Excitation frequency } \\
\text { range }\end{array}$ & $50 \mathrm{~Hz}<\mathrm{f}<20 \mathrm{kHz}$. \\
\hline Power consumption & $P<1 W$. \\
\hline Supply current & 5 to $10 \mathrm{~mA}$. \\
\hline $\begin{array}{l}\text { Operating temperature } \\
\text { range }\end{array}$ & -25 to $85^{\circ} \mathrm{C}$. \\
\hline
\end{tabular}

Some additional considerations $\left(C_{i}, i=1,2,3\right)$ for the LVDT design are listed below:

$>$ C1- Rate between the LVDT core radius and length: $r_{i} / L=0.05$.

$>$ C2- The number of turns in the secondary winding should be as large as possible to produce higher sensitivity.

$>$ C3- The wire of the secondary coils could be thinner.

In order to characterize the LVDT design, a common ferrite $\mathrm{Mn}-\mathrm{Zn}$ core $85 \mathrm{~mm}$ in length and $8.9 \mathrm{~mm}$ in diameter has been considered; hence, a range of $2.5 \mathrm{~cm}<x<5 \mathrm{~cm}$ is convenient. From the design: $C 1$, rate $r_{i} / L=0.052$. The LVDT design is shown in Figure 2. The core extends partway into each secondary coil even when the core is positioned toward either end at full stroke.
Then, with the geometric and electrical specifications, it is possible to obtain the number of turns in each coil. Basically, the LVDT consists of three coils spaced evenly along an insulated rod with the center primary coil $(P)$ and the outer secondary coils $\left(S_{1}\right.$ and $\left.S_{2}\right)$. The length of each coil is the same; thus, $P=S_{1}=S_{2}=12.5 \mathrm{~mm}$. Keeping in mind that, and taking into consideration the specifications described in this section (such as excitation voltage range, power consumption and the bobbin's radius), the number of turns in each coil is calculated as well as the diameter of the magnet wire. Thus, the LVDT should have 366 turns for the primary coil and the secondary coils. The magnet wire, according to American Wire Gauge (AWG) standards, is 37-wire gauge.

\section{Experimental results and discussion.}

A wave generator was connected to the primary coil. As the micrometer attached to the movable core was moved, the induced current to the secondary coil varied. The induced voltage in the secondary coil was measured for a range of linear displacement of $\pm 19 \mathrm{~mm}$, with respect to the central position of the movable core.

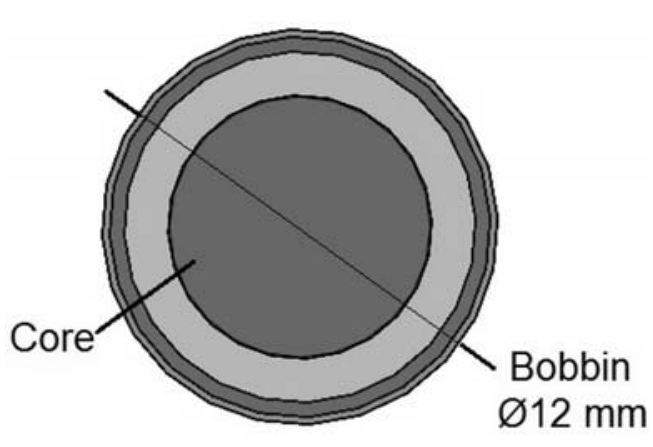

a) Zoom front view

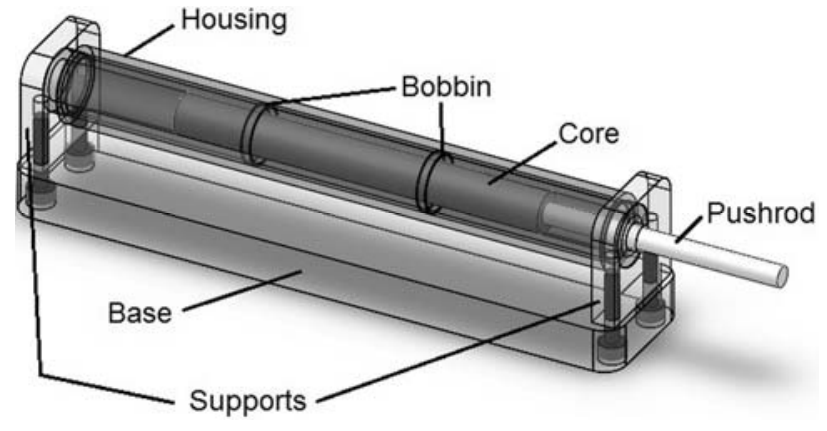

b) Trimetric view

Figure 2. LVDT design. 


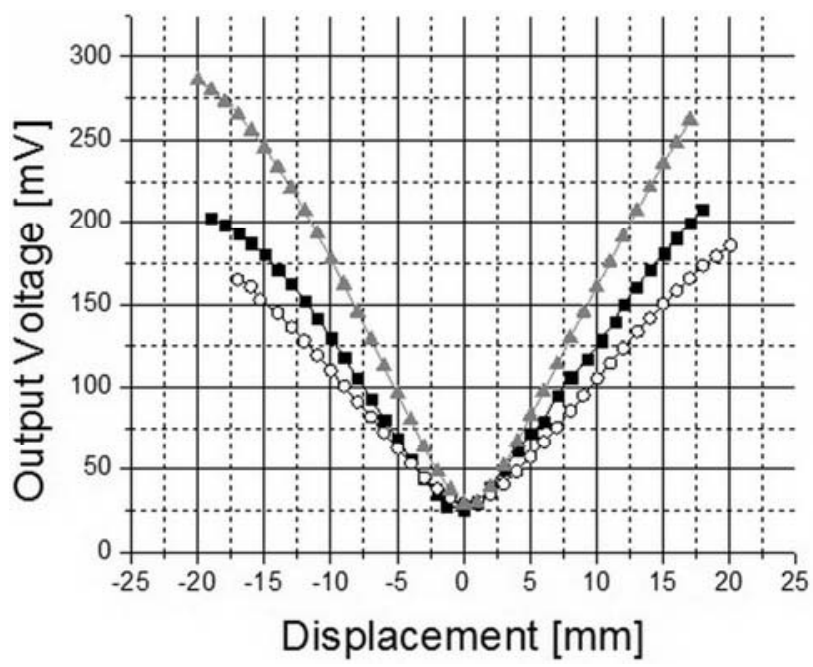

\begin{tabular}{lc}
\hline Material & $\begin{array}{c}\text { Standard deviation } \\
\text { of the measurements } \\
{[\mathrm{mm}]}\end{array}$ \\
\hline $\begin{array}{c}\text { Nickel steel } \\
\mathrm{Fe}, 50 \% \mathrm{Ni}\end{array}$ & 0.01 \\
\hline $\begin{array}{l}\text { Ferrite } \\
\text { Mn-Zn }\end{array}$ & 0.06 \\
\hline $\begin{array}{l}\text { Supermendur } \\
49 \% \mathrm{Fe}, 49 \% \mathrm{Co}, 2 \% \mathrm{~V}\end{array}$ & 0.02 \\
\hline
\end{tabular}

Figure 3. Displacement characterization of three different LVDT cores.

After completion of the procedure of the experimental setup, a voltage source of $2 \mathrm{~V}_{\mathrm{pp}}$, with an excitation frequency of $400 \mathrm{~Hz}$, suitable frequency to avoid the core losses [23], was applied to the primary coil of the LVDT. A total of three excursion measurements values were recorded into the micrometer range for each material, which were 38 turn steps of $1 \mathrm{~mm}$ linear displacement. The $0.01 \mathrm{~mm}$ linear resolution of each micrometer turn step was easily measured. The recorded data were the LVDT's output peak to peak voltage at the secondary coils measured with an oscilloscope. The displacement measurements for three different core materials are shown in Figure 3. The three full excursion measurements of each material were averaged in order to obtain the following graph:

The results of the displacement measurements for the LVDT soft magnetic core are summarized in Table 5.

\begin{tabular}{c|c|c|} 
& $\begin{array}{c}\text { Sensitivity } \\
{[\mathrm{V} / \mathrm{mm}]}\end{array}$ & $\begin{array}{c}\text { Linearity } \\
{\left[r^{2} \text { value }\right]}\end{array}$ \\
\hline $\begin{array}{c}\text { Nickel steel } \\
(\text { Fe, } 50 \% \mathrm{Ni})\end{array}$ & 13.85 & 0.9974 \\
\hline $\begin{array}{c}\text { Ferrite } \\
(\mathrm{Mn}-\mathrm{Zn})\end{array}$ & 10.15 & 0.9973 \\
\hline $\begin{array}{c}\text { Supermendur } \\
(49 \% \mathrm{Fe}, 49 \% \mathrm{Co}, \\
2 \% \mathrm{~V})\end{array}$ & 7.895 & 0.9953
\end{tabular}

Table 5. Comparison of sensitivity and linearity. Test conditions: $\mathrm{Ve}=2 \mathrm{Vpp}$ at $400 \mathrm{~Hz}$.
Since linearity corresponds to a measurement of the dependence of the input data versus the output data, it is linked to the correlation coefficient based on a least-squares regression of the displacement $(D)$ and the output voltage (OV).

If we let $O V_{\text {est }}$ denote the estimated value of $O V$ for a given value of $D$, as obtained from the regression curve of $O V$ on $D$, then the correlation coefficient can be computed from the result

$$
r^{2}=\frac{\sum\left(O V_{e s t}-\overline{O V}\right)^{2}}{\sum(O V-\overline{O V})^{2}}
$$

Hence, $r^{2}$ measures how well the least-squares regression line fits the sample data. Here, as usual, a bar indicates the mean value.

It is shown that the LVDT nickel steel core has great linearity and good sensitivity of $13.85 \mathrm{~V} / \mathrm{mm}$. The resulting sensitivity and linearity of the LVDT's ferrite and supermendur core is lower than that of the nickel steel core. The reason for such low sensitivity is that all these materials have also different resistivity; therefore, they are differently affected by eddy current effects. In addition, since these cores are not a closed magnetic circuit, they suffer also from demagnetization effects. In each case, the linearity becomes more acceptable when we reduce the core position range around the null 
position (for example, from $-15 \mathrm{~mm}$ to $15 \mathrm{~mm}$ ). The curve is symmetric with respect to the null position because of the complete symmetry of the device.

In that way, the main properties related to the implementation and performance of an LVDT core have been proposed. According to this approach, nickel steel replaces traditional materials, such as ferrite, as a core for the application of an LVDT design. Actually, at least four different materials can replace the traditional one: the first four materials shown in Table 4. The order of priority is as follows: 1) Supermendur $(49 \% \mathrm{Fe}, 49 \% \mathrm{Co}$, $2 \% \mathrm{~V}), 2)$ nickel steel $(\mathrm{Fe}, 50 \% \mathrm{Ni}), 3)$ nickel steel $(\mathrm{Fe}, 78 \% \mathrm{Ni})$, and 4$)$ iron $(99.95 \%)$. They are arranged this way based on the outcome of the selection process. At this point, the cost of each material has not been considered yet.

The order of priority changes when the cost of each material is considered. To the authors' knowledge, the cost ratio for each magnetic material is as shown in Figure 4. The cost ratio for each material is based on nickel steel 50 because it is the cheapest of the previously mentioned materials; thus, the cost ratio for nickel steel 50 is 1 , as Figure 4 shows. Iron is four times more expensive than nickel steel 50; hence, the cost ratio for iron is 4 , and so forth. The cost is subject to change due to market fluctuations.

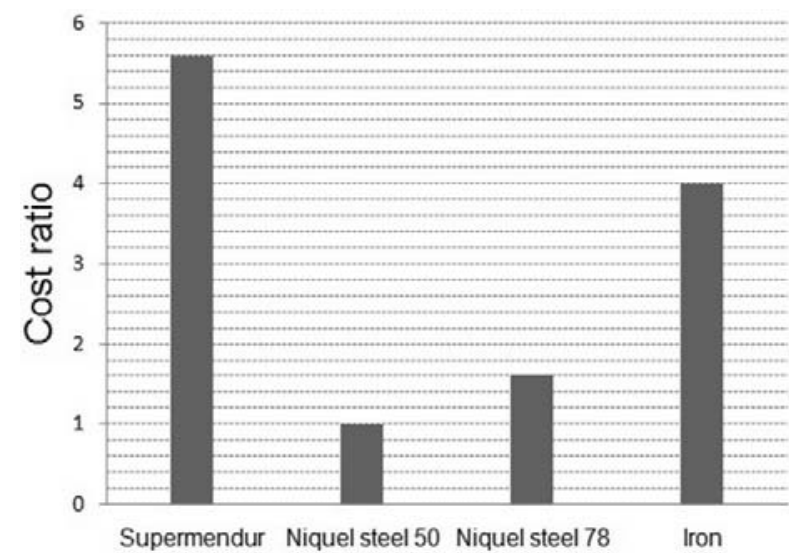

Figure 4. Materials cost ratio.
When the cost of each material is considered, the order of priority changes as follows: 1) nickel steel $(\mathrm{Fe}, 50 \% \mathrm{Ni}), 2)$ nickel steel $(\mathrm{Fe}, 78 \% \mathrm{Ni}), 3$ ) iron $(99.95 \%)$, and 4$)$ Supermendur $(49 \% \mathrm{Fe}, 49 \% \mathrm{Co}$, $2 \% \mathrm{~V})$. As can be seen, nickel steel $(\mathrm{Fe}, 50 \% \mathrm{Ni})$ is still the best option to replace ferrite material in LVDT core applications, even when the cost of each material is included.

Regarding the magnetic properties of the material selected, nickel steel 50 offers high saturation flux density, a relatively good permeability at high flux density, low coercive force and a moderate loss at low frequencies. Nickel steel 50 has low electric resistance, $40 \times 10^{-6} \Omega-\mathrm{cm}$, in comparison to traditional ferrites (Ferrite-MnZn: 10 to $100 \Omega-\mathrm{cm}$ ), hence, considerably higher magnetic losses are expected; however, a moderate loss is obtained with this approach since the losses by eddy currents are proportional to the square of the material's thickness perpendicular to the flux flow, frequency, and induction, but inversely proportional to resistivity. At very high frequencies, a very high resistivity is required; while in the low frequencies domain, high permeability and magnetization at saturation and low coercivity become the main characteristics.

Ferrites are very attractive materials from the commercial point of view because of their easy preparation and versatility to be used in a wide range of applications. In applications where the geometry of the core is prone to suffer changes, ferrite materials become unsuitable because of their characteristics, especially when a machining process is used to adapt the core geometry to the device in the designing phase. Based on the requirements, nickel steel is selected as an ideal material for core LVDT applications because of its mechanical and electrical properties, performance and availability.

\section{Conclusions}

A theoretical and experimental procedure to select core materials for LVDT applications was presented. Alternatives for soft magnetic materials, less traditional in applications as core material, have been explored. A simple and effective strategy to select finite options for core materials 
based on requirements has been proposed and validated by means of the construction of a prototype of LVDT. Following this strategy, a collection of soft magnetic materials arranged by the relative permeability value was identified. In order to validate the material identified, a prototype of LDTV was designed and fabricated. Test results indicate that nickel steel $(\mathrm{Fe}, 50 \% \mathrm{Ni})$ has better linearity and sensitivity than common $\mathrm{Mn}-\mathrm{Zn}$ ferrite and Supermendur. In that manner, the possibility of using a different material in applications where core geometry must change, without excessive care in the handling, was discussed. Considering the cost of the selected material, the requirements exposed in this work and the experimental results, the best material for an LVDT core is nickel steel ( $\mathrm{Fe}, 50 \% \mathrm{Ni})$. In addition, the information collected in this study allows the users not only to qualify the materials according to their needs, but also to customize the core materials for specific applications. One of these applications is a sensor for micrometric displacements for the characterization of micromachine tools.

\section{Acknowledgments}

This work was supported by CONACYT grant 60895 . Thanks are also due to Dr. José Israel Betancourt-Reyes for providing a piece of Mumetal for preliminary tests.

\section{References}

[1] D. S. Nyce, Linear Position Sensors: Theory and Application, 2004.

[2] K. Ma, Ghasemi-Nejhad, N., Smart Composite Systems with Nanopositioning, in Handbook of Nanophysics: Funtional Nanomaterials, K. D. Sattle (Eds.), ed: CRC Press, 2011, pp. 8.1-8.23.

[3] H. N. Norton, Sensor and Analyzer Handbook, Prentice-Hall, 1982.

[4] M. Félix, Lizárraga, A., Islas, A., González, A., Analysis of a ferrofluid core LVDT displacement sensor, in IECON 2010 - 36th Annual Conference on IEEE Industrial Electronics Society Glendale, AZ, 2010, pp. 1769-1772.

[5] J. K. Sykulski, Sysulska, E. Hughes, S. T., Applications of Finite Element Modelling in LVDT Design, COMPEL: The International Journal for Computation and Mathematics in Electrical and Electronic Engineering, 11(1) (1992) pp. 129-134.
[6] S. Taifour, Al-Sharif, L., Kilani, M., Modelling \& Design of a Linear Variable Differential Transformer, in Proc. of the International Conference on Modeling and Simulation (MS'08), Petra, Jordan, 18-20 November, 2008.

[7] A. Masi, Danisi, A., Losito, R., Martino, M., Spiezia, G., Study of magnetic interference on a LVDT prototype, in Instrumentation and Measurement Technology Conference (I2MTC), 2010 IEEE CERN, Eur. Organ. for Nucl. Res., Geneva, Switzerland 2010, pp. 219-223.

[8] M. Martino, Danisi, A., Losito, R., Masi, A., Spiezia, G., Design of a Linear Variable Differential Transformer with High Rejection to External Interfering Magnetic Field, Transactions on Magnetics, IEEE, 46(2) (2010) pp. 674-677.

[9] Ferroxcube, Soft Ferrites Data Handbook 2009 [Online].

[10] S. Chikazumi, Physics of ferromagnetism: Oxford University Press, 2005.

[11] B. Williams, W., Soft Magnetic Materials, in Power Electronics: Devices, Drivers, Applications and Passive Components, ed. McGraw Hill, 1992, pp. 618-679.

[12] K. Hoselitz, Magnetically Soft Materials, in Ferromagnetic properties of Metals and Alloys, ed. Clarendon Press (Oxford), GB: Oxford Univ. Press, 1952, pp. 238-239.

[13] G. E. Fish, Soft Magnetic Materials, Proceedings of the IEEE, 78(6) (1990) pp. 947-972.

[14] P. G. Gogue, Stupak, J. J., A review of steel materials in motion devices, in PCIM 1990 Conference, Philadelphia, PA. December 1990.

[15] D. W. Callister, Magnetic Properties, in Materials Science and Engineering, An Introduction, 7th Ed. ed. John Willey \& Sons, Inc., 2007, pp. 19-56.

[16] J. Gersten, Smith, F., Magnetic materials, in The physics and chemistry of materials, ed. John Wiley Sons, Inc., 2001, pp. 603-644.

[17] H. Gavrila, Ionita, V., Crystalline and amorphous soft magnetic materials and their applications - Status of art and challenges, Journal of Optoelectronics and Advanced Materials, 4(2) (2002) pp. 173-192.

[18] K. H. J. Buschow, de Boer, F. R., Physics of Magnetism and Magnetic Materials, ed. Kluwer Academic Publisher, New York, 2003.

[19] Soft Ferrites, A user's guide, ed. Magnetic Materials Producer Association: MMPA Soft Ferrite Division, 1998. 
[20] Soft ferrites A user's guide, in Magnetic Materials Producers Association, 1998.

[21] Magnetic Cores for Switching Power Supplies, in Magnetics Division of Spang \& Company, 2001.

[22] Soft Magnetic Application Guide, in Group Arnold The Magnetic Products Group of SPS Technologies, 2000.

[23] C. McLyman, Magnetic Materials and Their Characteristics, in Transformer and Inductor Design Handbook, D. Marcel, Inc. (Eds.) 2004, pp. 85-143.

[24] D. Benjamin, Metals Handbook: Properties and Selection: stainless steels, tool materials and special purpose metals, 9th Ed. vol. 3, 1980.

[25] G. W. Elmen, Magnetic Alloys of Iron Nickel, and Cobalt, Transactions of the American Institute of Electrical Engineers, IEEE, 54(12) (1935) pp. 1292-1299.

[26] M. Rashid, Power electronics: Circuits, devices and applications, 3th Ed. Prentice Hall, Inc., 2004.

[27] A. Barua. Lecture Series on Industrial Instrumentation, Department of Electrical Engineering, IIT Kharagpur Available: http://nptel.iitm.ac.in (Accessed: November 2010).

[28] J. Webster, Mechanical Variables Measurement Solid, Fluid and Thermal, CRC Press. 1999. 